\title{
Three-dimensional numerical study for laminar natural convection within a rectangular solar chimney
}

Prof. Dr. Jalal M. Jalil ${ }^{1}$, Assist. Prof. Dr. Hussein M. Salih ${ }^{1}$, Assist. Prof. Dr. Adel H. Ayaal ${ }^{1}$

${ }^{1}$ Department of Electromechanical Engineering, University of Technology, Baghdad, Iraq

\begin{abstract}
A numerical study of three - dimensional, steady, laminar and incompressible natural convection of air $(\mathrm{Pr}=0.72)$ within a rectangular solar chimney is presented. Partial differential equations for conservation of mass, momentum and energy equations are solved by finite volume method with staggered grid arrangement. SIMPLE algorithm is applied to solve the set of discretization equations. The numerical results are compared with those of previous published work under the same conditions and gives a good agreement. The influence of changing in chimney dimension (thickness and height) and the inlet air temperature on the amount of induced flow rate is studied. From the presented results the optimal design for the chimney can be achieved.
\end{abstract}

Keywords: CFD, natural convection, vertical duct, solar chimney, numerical analysis.

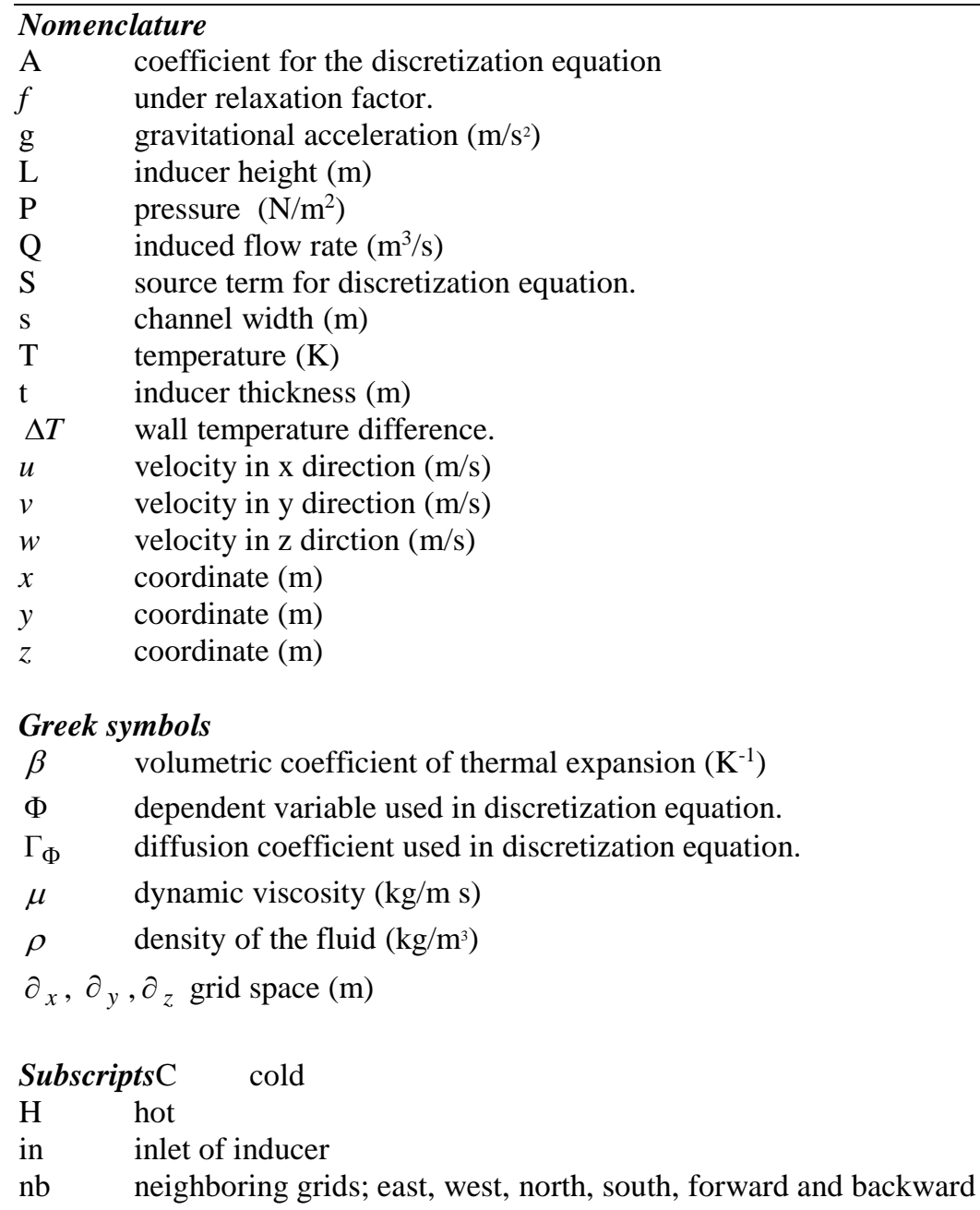




\section{Introduction}

Natural convection heat transfer is an attractive heat transfer mechanism due to its reliability, simplicity, and cost effectiveness. In particular, natural convection in vertical channel is of interest in many applications, such as cooling of electronic equipments, heating of building via Trombe walls, and solar systems. [1]

The heat transfer and natural convective flow in vertical open channel are induced due to the temperature difference between front and rear surface. The thermal design of a naturally ventilated device depends on geometric and operating conditions: shape, dimensions of the system, flow areas of the inlet/outlet openings, and the wall temperature difference. We can take advantage of this fact in heating buildings by exploiting existing spaces in the aspects of the buildings and their exposure to the sun during the day, where the channel will be designed in the form of rectangular and open ends to knowledge of the behavior of flow and the amount of heat transmitted to the flow, the front face of the channel is the cold face either the back side shall be hot as shown in Figure (1).

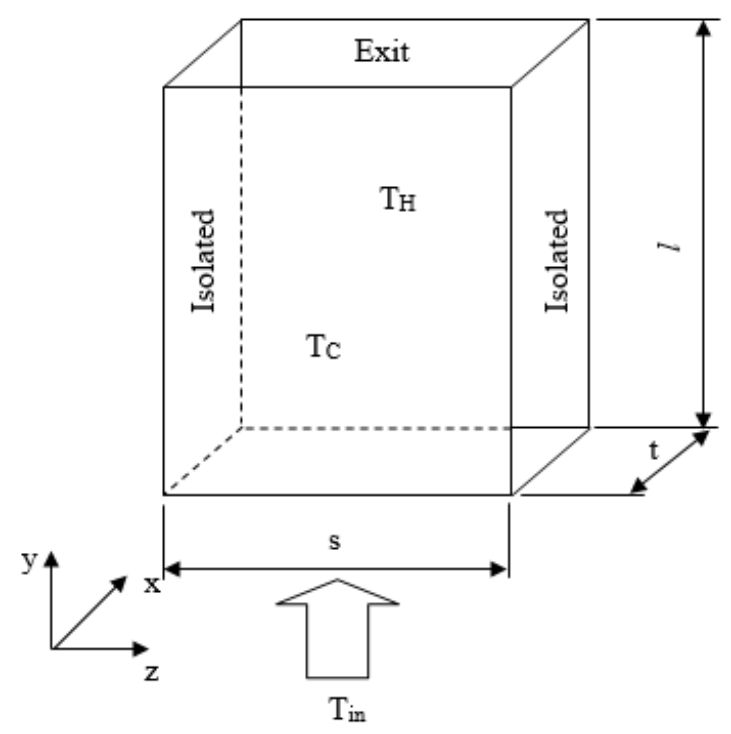

Fig. 1 Geometry and boundary conditions for the problem.

The natural convection heat transfer in vertical open duct flows induced by the thermal buoyancy force has been studied extensively in the literature for different geometries. Lee and Yan [1] presented a numerical analysis to examine the characteristics of laminar natural convection in vertical channel with unheated entry and unheated exit. Naylor et al. [2] solved the problem of natural convection between isothermal vertical plates. They assumed the flow to be fully developed at the channel exit section and a non-trivial channel inlet flow condition. Numerical investigation on the transport mechanism of laminar natural convection motion of a Trombe-wall channel and turbulent combined convection between two vertical parallel plates that were uniformly heated were performed by Inagaki and Komori [3]. Fedorov and Viskanta [4] studied the induced flow and heat transfer in an asymmetrically heated, vertical parallel-plate channel. The thermal buoyancy force induced airflow in the channel. A low Reynolds number $k-\varepsilon$ turbulent model was used in conjunction with heat transfer analysis. Higuera and Ryazantsev [5] presented an analysis of the laminar natural convection flow due to a localized heat source on the centerline of a long vertical channel or pipe whose walls are kept at a constant temperature. Stationary solutions are obtained for infinitely long and finite length channels. Habib et al. [6] presented the results of velocity measurements of natural convection in symmetrically and asymmetrically heated vertical channels. Anwar [7] investigated the problem of buoyancy driven turbulent natural convection flow in a vertical channel numerically. The investigation is limited to vertical channels of uniform crosssection (parallel-plate channels) but with different modes of heating. Ben-Mansour et al. [8] presented the results of a numerical investigation of turbulent natural convection flow and heat transfer in a vertical parallel-plate open channel using six different turbulence models and four different inlet boundary conditions. Tanda [9] investigated the effect of repeated horizontal protrusions on the free convection heat transfer in a vertical, asymmetrically heated, channel experimentally. Mokni [10] expressed a numerical investigation of mixed convection in a vertical heated channel. Salih [11] presented a numerical investigation to estimate the induced flow rate for a laminar natural convection flow of air in a vertical channel with isothermal walls conditions (one hot and another is cold). The twodimensional governing equations have been solved using finite volume method.

As seen, studies on the natural convection heat transfer in vertical rectangular ducts exist in the open literature. This motivated the present study. Numerical analysis is performed to investigate the natural convection heat transfer in vertical rectangular solar chimney. The boundary conditions used are considered in a way that provides a real application of the solar chimney. A threedimensional, steady, laminar and incompressible natural convection of air $(\operatorname{Pr}=0.72)$ within a chimney is studied numerically. Partial differential equations for conservation of mass, momentum and energy equations are solved by finite volume method with staggered grid arrangement. SIMPLE algorithm is applied to solve the set of discretization equations.

\section{Problem Formulations}

A schematic of the physical situation to be investigated is a three-dimensional rectangular inducer which is shown in Figure 1. Each of the two- 
sided walls, right located at $\mathrm{z}=0$ and the left at $\mathrm{z}=\mathrm{s}$, are maintained isolated. Front vertical wall located at $x=0$ is a cold wall having a temperature TC while the backward vertical wall which is located at $\mathrm{x}=\mathrm{t}$ is a hot wall of $\mathrm{T}_{\mathrm{H}}$. The bottom and top of the inducer located at $\mathrm{y}=0$ and $\mathrm{y}=l$ represent an entry and exit of air to the inducer respectively. The fluid within the inducer is an air $(\mathrm{Pr}=0.72)$.

\section{Governing equations}

The flow within the inducer is assumed to be steady incompressible three-dimensional laminar flow. The governing equations for three dimensional, steady, and laminar flow are represented by continuity, momentum and energy equation as follow:

Continuity:

$\frac{\partial(\rho u)}{\partial x}+\frac{\partial(\rho v)}{\partial y}+\frac{\partial(\rho w)}{\partial z}=0$

$\mathrm{x}$-direction momentum equation

$$
\begin{aligned}
& \frac{\partial(\rho u u)}{\partial x}+\frac{\partial(\rho v u)}{\partial y}+\frac{\partial(\rho w u)}{\partial z}=\frac{\partial}{\partial x} \\
& {\left[\mu\left(\frac{\partial u}{\partial x}\right)\right]+\frac{\partial}{\partial y}\left[\mu\left(\frac{\partial u}{\partial y}\right)\right]+\frac{\partial}{\partial z}} \\
& {\left[\mu\left(\frac{\partial u}{\partial z}\right)\right]+S_{u}}
\end{aligned}
$$

$\mathrm{y}$-direction momentum equation

$$
\begin{aligned}
& \frac{\partial(\rho u v)}{\partial x}+\frac{\partial(\rho v v)}{\partial y}+\frac{\partial(\rho w v)}{\partial z}=\frac{\partial}{\partial x} \\
& {\left[\mu\left(\frac{\partial v}{\partial x}\right)\right]+\frac{\partial}{\partial y}\left[\mu\left(\frac{\partial v}{\partial y}\right)\right]+\frac{\partial}{\partial z}} \\
& {\left[\mu\left(\frac{\partial v}{\partial z}\right)\right]+S_{v}}
\end{aligned}
$$

$\mathrm{z}$-direction momentum equation

$$
\begin{aligned}
& \frac{\partial(\rho u w)}{\partial x}+\frac{\partial(\rho v w)}{\partial y}+\frac{\partial(\rho w w)}{\partial z}=\frac{\partial}{\partial x} \\
& {\left[\mu\left(\frac{\partial w}{\partial x}\right)\right]+\frac{\partial}{\partial y}\left[\mu\left(\frac{\partial w}{\partial y}\right)\right]+\frac{\partial}{\partial z}} \\
& {\left[\mu\left(\frac{\partial w}{\partial z}\right)\right]+S_{w}}
\end{aligned}
$$

$$
\begin{aligned}
& \frac{\partial(\rho u T)}{\partial x}+\frac{\partial(\rho v T)}{\partial y}+\frac{\partial(\rho w T)}{\partial z}=\frac{\partial}{\partial x} \\
& {\left[\Gamma\left(\frac{\partial T}{\partial x}\right)\right]+\frac{\partial}{\partial y}\left[\Gamma\left(\frac{\partial T}{\partial y}\right)\right]+\frac{\partial}{\partial z}} \\
& {\left[\Gamma\left(\frac{\partial T}{\partial z}\right)\right]+S_{T}}
\end{aligned}
$$

Where

$$
\begin{aligned}
& S_{u}=-\frac{\partial P}{\partial x}+\frac{\partial}{\partial x}\left[\mu\left(\frac{\partial u}{\partial x}\right)\right]+\frac{\partial}{\partial y} \\
& {\left[\mu\left(\frac{\partial v}{\partial x}\right)\right]+\frac{\partial}{\partial z}\left[\mu\left(\frac{\partial w}{\partial x}\right)\right]} \\
& S_{v}=-\frac{\partial P}{\partial y}+\frac{\partial}{\partial x}\left[\mu\left(\frac{\partial u}{\partial y}\right)\right]+\frac{\partial}{\partial y} \\
& {\left[\mu\left(\frac{\partial v}{\partial y}\right)\right]+\frac{\partial}{\partial z}\left[\mu\left(\frac{\partial w}{\partial y}\right)\right]+} \\
& \rho g \beta\left(T-T_{c}\right) \\
& S_{w}=-\frac{\partial P}{\partial z}+\frac{\partial}{\partial x}\left[\mu\left(\frac{\partial u}{\partial z}\right)\right]+\frac{\partial}{\partial y} \\
& {\left[\mu\left(\frac{\partial v}{\partial z}\right)\right]+\frac{\partial}{\partial z}\left[\mu\left(\frac{\partial w}{\partial z}\right)\right]}
\end{aligned}
$$

In thermal energy equation the radiation heat transfer, the viscous dissipation, pressure work and Joule heating are ignored, so the source term $S_{T}$ becomes

$$
S_{T}=0
$$

\section{Boundary conditions}

The boundary conditions to be satisfied for the problem are expressed as:

- At the right wall

$\mathrm{z}=0,0<y<l, 0<x<t, u=v=w=0, \frac{\partial T}{\partial z}=0$

- At the left wall

$$
\begin{aligned}
& \mathrm{z}=\mathrm{s}, 0<y<l, 0<x<t, \quad u=v=w=0, \\
& \frac{\partial T}{\partial z}=0
\end{aligned}
$$

- At the front 
$\mathrm{x}=0, \quad 0<y<l, \quad 0<z<s, \quad u=0, \quad v=0, \quad w=0$,

$T=T_{C}$.

- At the backward wall

$\mathrm{x}=\mathrm{t}, 0<y<l, 0<z<s, \quad u=0, v=0, w=0$,

$T=T_{H}$.

$$
\begin{aligned}
& \text { - At entry } \\
& \begin{array}{l}
\mathrm{y}=0 \\
\frac{\partial u}{\partial y}=\frac{\partial v}{\partial y}=\frac{\partial w}{\partial y}=0, T=T_{\text {in }}
\end{array}
\end{aligned}
$$$$
\text { - At exit }
$$$$
\mathrm{y}=l, 0<x<t, 0<z<s, \frac{\partial u}{\partial y}=\frac{\partial v}{\partial y}=\frac{\partial w}{\partial y}=0
$$$$
\frac{\partial T}{\partial y}=0
$$

\section{Method of solution}

The SIMPLE algorithm by Patankar and Spalding [12] is applied to solve the conservation equation of mass, momentum and energy. The transport equations for continuity, momentum and energy equations, all can be written in general form in three-dimensional geometry as follow:

$$
\begin{aligned}
& \frac{\partial(\rho u \Phi)}{\partial x}+\frac{\partial(\rho v \Phi)}{\partial y}+\frac{\partial(\rho w \Phi)}{\partial z}=\frac{\partial}{\partial x} \\
& {\left[\Gamma_{\Phi}\left(\frac{\partial \Phi}{\partial x}\right)\right]+\frac{\partial}{\partial y}\left[\Gamma_{\Phi}\left(\frac{\partial \Phi}{\partial y}\right)\right]+\frac{\partial}{\partial z}} \\
& {\left[\Gamma_{\Phi}\left(\frac{\partial \Phi}{\partial z}\right)\right]+S_{\Phi}}
\end{aligned}
$$

Equation (10) is re-arrangement of algebraic equation of the form:

$$
\left(A_{i}-S_{P}\right) \Phi_{P}=\sum_{n b} A_{i} \Phi_{i}+S_{u}
$$

The set of finite volume equations is solved by using an iteration method, starting from the solution of a previous run as initial condition. Numerical stability is enhanced by the choice of approximate relaxation factor $f$ which is defined as [13]:

$$
\Phi_{P}^{n}=f \Phi_{P}+(1-f) \Phi_{P}^{o}
$$

Where, $\Phi_{P}^{O} \square$ is the value of $\Phi$ from the previous iteration, $\Phi_{P}$ is the values obtained from the solved equation (11) and $\Phi_{P}^{n}$ is the new value. The value of the relaxation factor $f$ can be in the range of $0<f \leq 1$.

\section{Grid independency}

In the present work, four sets of grid without clustering are tested $(51,51,11),(71,71,11)$, $(91,91,11)$ and $(111,111,11)$, where the later $(111,111,11)$ with iteration number equal to 8000 is chosen because this set ensures good results, as shown in Figures $2 \& 3$.

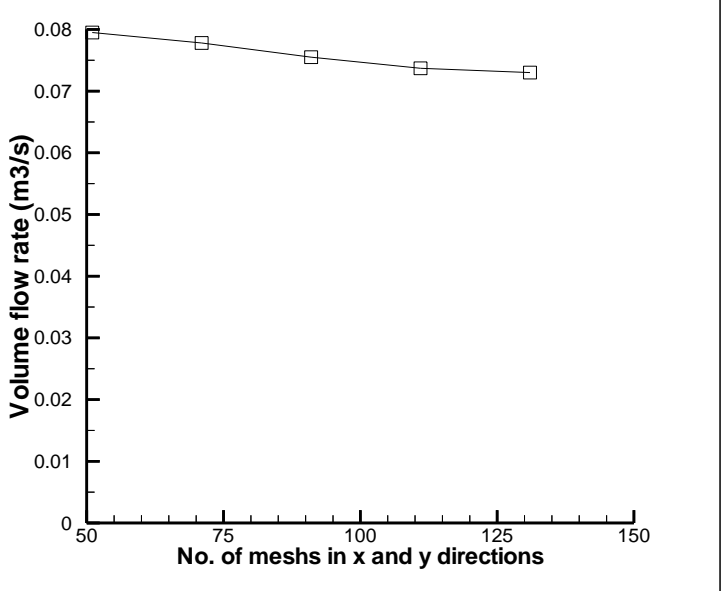

Fig. 2 Grid independency

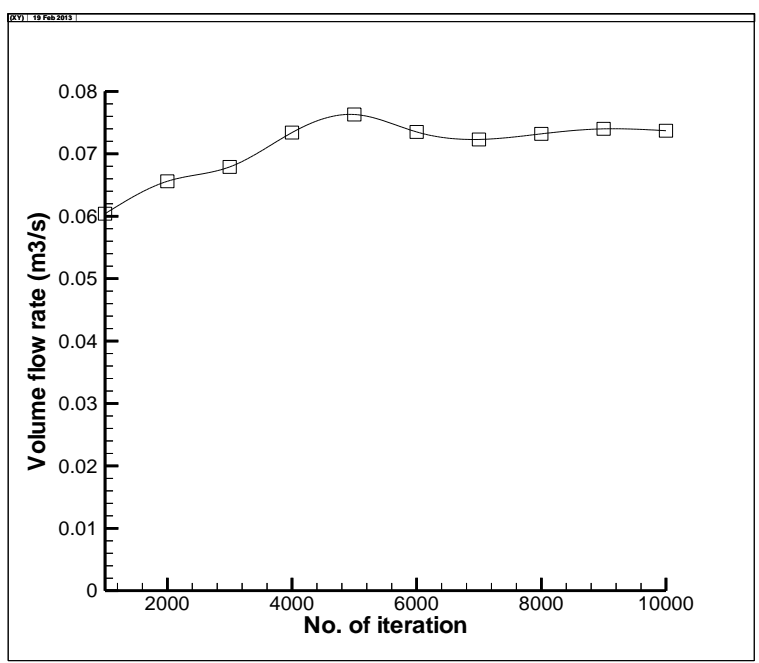

Fig. 3 Variation of volume flow rate with no. of iteration

\section{Validation}

In order to verify the accuracy of the present numerical investigation, the numerical results are compared with the previously published works of Lee and Yan [1] for a similar problem ( vertical inducer $)$ under conditions of $\left(\mathrm{T}_{\mathrm{H}}=\mathrm{T}_{\mathrm{C}}=40^{\circ} \mathrm{C}\right.$ and $\mathrm{T}_{\mathrm{in}}=20^{\circ} \mathrm{C}$ ) with inducer thickness equal to $0.02 \mathrm{~m}$. 


\begin{tabular}{|c|c|c|c|c|}
\hline \multirow{2}{*}{$\begin{array}{c}\text { Thickness } \\
(\mathrm{m})\end{array}$} & Inlet & \multicolumn{3}{|c|}{ Height $(\mathrm{m})$} \\
\cline { 3 - 5 } & $\mathrm{C}$ & 1.0 & 1.5 & 2.0 \\
\hline 0.03 & 10 & 0.0196 & 0.0244 & 0.0310 \\
\hline 0.03 & 15 & 0.0171 & 0.0213 & 0.0271 \\
\hline 0.03 & 20 & 0.0145 & 0.0183 & 0.0222 \\
\hline 0.04 & 10 & 0.0291 & 0.0406 & 0.0535 \\
\hline 0.04 & 15 & 0.0252 & 0.0348 & 0.0462 \\
\hline 0.04 & 20 & 0.0211 & 0.0289 & 0.0380 \\
\hline 0.05 & 10 & 0.0369 & 0.0566 & 0.0757 \\
\hline 0.05 & 15 & 0.0320 & 0.0494 & 0.0649 \\
\hline 0.05 & 20 & 0.0265 & 0.0415 & 0.0530 \\
\hline
\end{tabular}

elsewhere in the flow. Thus, the buoyancy tends to equalize the temperature in the fluid.

As it can be seen from Figure 4, the comparison gives a good agreement.

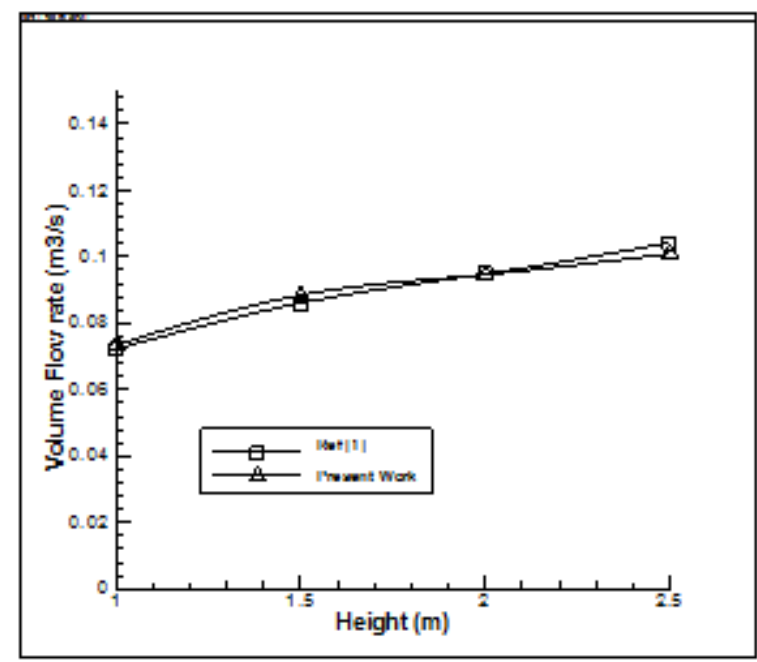

Fig. 4 Comparision with Ref [1] work.

\section{Results and discussion}

The flow induced by natural convection and heat transfer within a rectangular solar chimney is studied numerically to achieve an optimal design for the chimney. The effect of changing in inlet air temperature and dimensions of chimney (thickness and height) on the amount and temperature of induced air are studied.

As maintained above, the present work consists studying the effect of changing inlet air temperature where three values are examined as (10, 15 and 20) ${ }^{\circ} \mathrm{C}$. As for the dimensions of chimney, also three values of thickness as $(0.03,0.04$ and 0.05$) \mathrm{m}$ are studied and three values of height as (1, 1.5 and 2) $\mathrm{m}$ are considered. See Table 1.

Figure (5) represents velocity vector and isothermal contour at the mid surface of inducer for one of the cases studied. As can be seen from these figures the effect of boundary layer is noticed by the reduction in the velocity in the region that adjacent to the walls of inducer, while the effect of the buoyancy is felt in the developing regions, where the buoyancy decreases the temperature in the region adjacent to the hot wall. While increasing the temperature
Table 1. Volume flow rate $\left(\mathrm{m}^{3} / \mathrm{s}\right)$ for different conditions
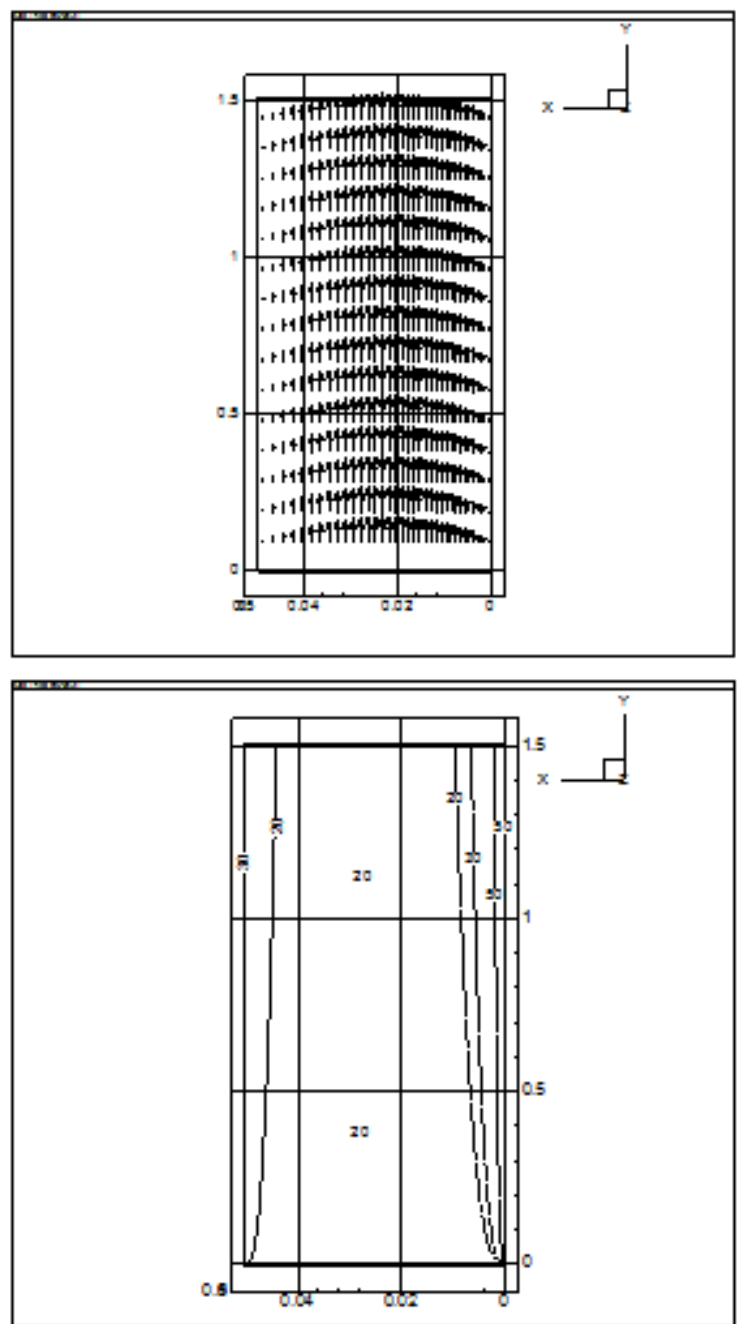

Fig. 5 Flow field and isothermal contours for thickness $=0.05 \mathrm{~m}$, height $=1.5 \mathrm{~m}, \mathrm{~T}_{\mathrm{in}}=20 \mathrm{C}$, $\max$ velocity $1.85 \mathrm{~m} / \mathrm{s}$.

The effect of variation in the inducer dimensions (thickness and height) on the amount of induced air is illustrated in Figures $6 \& 8$. As a result of increasing in the area of inlet port of the inducer by increasing the thickness, induced flow rate will be increased as it can be seen in Figures $6 \& 8$. It is worth mentioning, that any increasing in the thickness of chimney greater than $0.05 \mathrm{~m}$ leads to make a flow behavior like that for enclosure where there is a generation of reverse flow near the cold wall. According to this the amount of induced flow rate will be decreasing. In the other hand, the increasing in the height of the chimney leads to increase the area of the hot wall, as a result of this the amount of induced air will be increased as a reason of increasing in the source of inducing, and 
there is a rapid increasing in the amount of induced air whenever the chimney height increasing are seen.

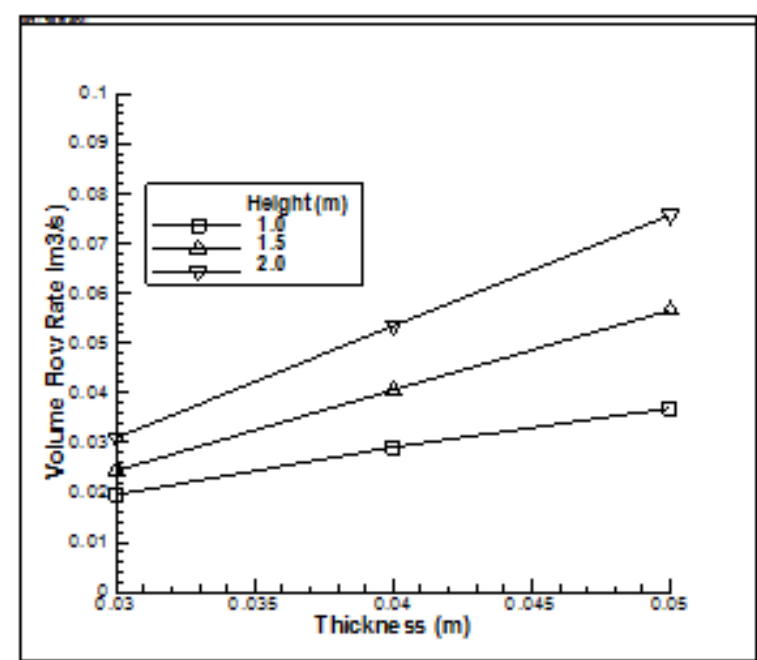

Fig. 6 Variation of volume flow rate with thickness for different height and $\mathrm{T}_{\text {in }}=10$.

The effect of variation in the inlet air temperature on the amount of the induced flow rate is expressed in Figures $7 \& 8$. There is a noticeable reduction in the amount of induced volume flow rate with increasing the temperature of the inlet air to the chimney, and the reduction descending with the decreasing the chimney height this is due to the decreasing in the buoyancy force as a result of decreasing in the temperature difference which is responsible for buoyancy force generating.

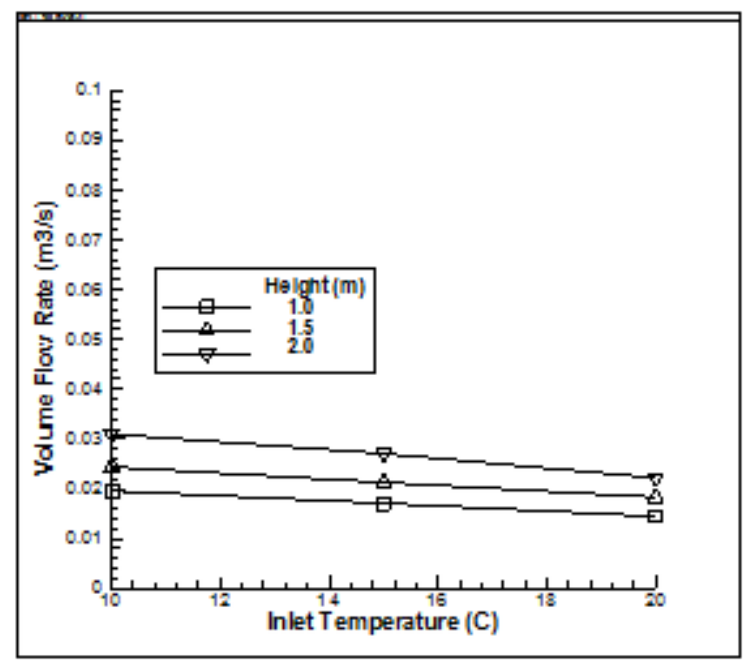

Fig. 7 Variation of volume flow rate with inlet temperature for different heights and thickness = $0.03 \mathrm{~m}$

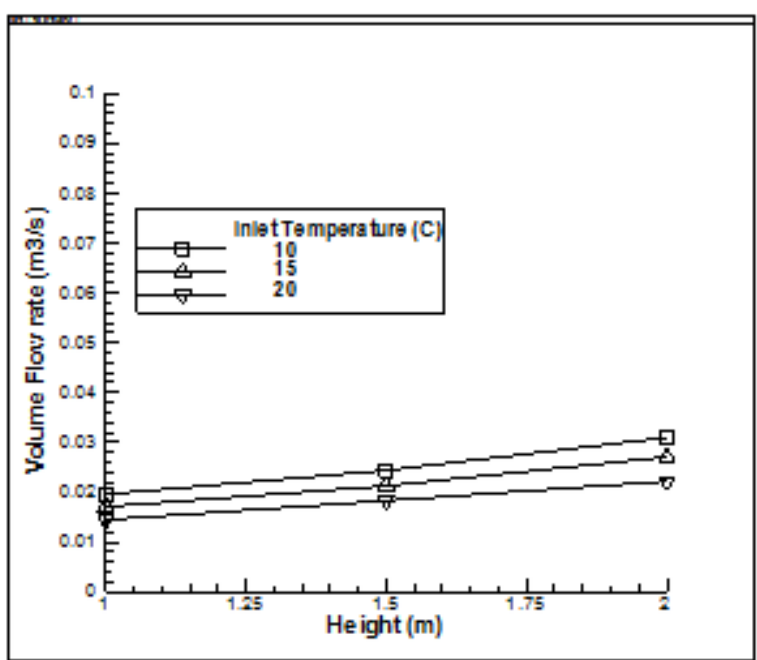

Fig. 8 Variation of volume flow rate with height for different inlet temperature and thickness $=0.03 \mathrm{~m}$

\section{Conclusions}

A numerical study of three -dimensional, steady and incompressible laminar natural convection of air $(\operatorname{Pr}=0.72)$ within a rectangular solar chimney is presented. Finite volume with staggered grid arrangement is used to solve the governing equations. The results show that the induced flow rate influenced by the chimney dimensions (thickness and height) and inlet air temperature. The induced flow rate increased with increasing the height and thickness of chimney, and it is found there is a limitation of this increasing as a result of the reverse flow formation with a further increasing in the thickness of chimney. In the other hand the induced flow rate reduced with the increasing inlet air temperature due to the decreasing in the buoyancy force. From these results the optimal design of the solar chimney can be achieved.

\section{$\underline{\text { References }}$}

[1] K. T. Lee and W.M. Yan "Laminar natural convection between partially heated vertical parallel plates" Int. J. Heat Mass Transfer, 29, 145-151 (1994) Springer-Verlag 1994 Taiwan, P.R.C.

[2] D. Naylor, J. M. Floryan, and J. D. Tarasuk, "A Numerical Study of Developing Free Convection between Isothermal Vertical Plates", Trans. ASME, Journal of Heat Transfer, 113(1991), pp. 620-626.

[3] T. Inagaki, K. Komori, "Numerical modeling on turbulent transport with combined forced and natural convection between two vertical parallel plates", Int. J. Comput. Meth. A 27 (4) (1995) 417-431.

[4] A. G. Fedorov and R. Viskanta, "Turbulent Natural Convection Heat Transfer in an Asymmetrically Heated, Vertical Parallel-Plate 
Channel", International Journal of Heat and Mass Transfer, 40(16) (1997), pp. 3849-3860.

[5] F.J. Higuera *, Yu.S. Ryazantsev, " Natural convection flow due to a heat source in a vertical channel", International Journal of Heat and Mass Transfer 45 (2002), pp. 2207-2212.

[6] M.A. Habib, S.A.M. Said, S.A. Ahmed, A. Asghar, "Velocity characteristics of turbulent natural convection in symmetrically and asymmetrically heated vertical channels", Experimental Thermal and Fluid Science 26 (2002) 77-87.

[7] Sohail Anwar, "Natural convection flow in parallel-plate vertical channels", M.Sc. Thesis submitted to The King Fahd University of Petroleum and Minerals (2003).

[8] R. Ben-Mansour, M.A. Habib, H.M. Badr, and S. Anwar," Comparison of different turbulence models and flow boundary condition in predicting turbulent natural convection in a vertical channel with isoflux plates", The Arabian Journal for Science and Engineering, Volume 32, Number 2B, 2007.
[9] Giovanni Tanda, "Natural convective heat transfer in vertical channels with low-thermal conductivity ribs", International Journal of Heat and Fluid Flow 29 (2008) pp. 1319-1325.

[10] A. Mokni, H. Mhiri, G. Le Palec , Ph. Bournot, " Mixed convection in a vertical heated channel: influence of the aspect ratio", International Journal of Engineering and Applied Sciences 5:1 (2009), pp.60-66.

[11] Hussein Majeed Salih," Numerical Simulation for Laminar Natural Convection with in a Vertical Heated Channel", Eng. And Tech. Journal, Vol. 19, No. 11, 2011.

[12] Patankar, S.V. and Spalding, D.B., " A calculation procedure for heat, mass and momentum transfer in three-dimensional parabolic flows." Int. J. Heat Mass Transfer, Vol. 3, 269-289, 1974.

[13] Patnkar, SV., "Numerical Heat Transfer nd Fluid Flow", McGraw-Hill, New York (1980). 